\title{
Acreditação dos Hospitais das Cidades Sede Bra- sileira na Copa do Mundo de Futebol em 2014
}

\author{
Rudimar Antunes da Rocha ${ }^{1}$ \\ Andreas Dittmar Weise ${ }^{2}$ \\ Charles Albino Schultz ${ }^{3}$ \\ Allan Augusto Platt ${ }^{4}$
}

\section{Resumo}

O artigo aborda a Acreditação Hospitalar como um parâmetro de qualidade das organizações hospitalares no Brasil e mundo. O foco foi identificar como os hospitais das cidades sede da Copa do Mundo de Futebol de 2014 estão classificados pela Organização Nacional de Acreditação (ONA) e Joint Commission on Accreditation of Hospitals (JCI) - Consórcio Brasileiro de Acreditação (CBA). O Manual Brasileiro de Acreditação estabelece três selos de qualidade hospitalar: Nível 1: Acreditado; Nível 2: Acreditado Pleno; e Nível 3: Acreditado com Excelência. Do ponto de vista metodológico, a pesquisa se caracterizou como do tipo exploratório, com abordagem tipo survey psicográfico, com a coleta intencional dos dados, isto é, as cidades sedes. A pesquisa teve um tratamento qualitativo e quantitativo. Os dados foram coletados nos meses de março e abril de 2011, através dos sites oficiais da ONA, JCI-CBA e FIFA na internet. Concluiu-se que as cidades de São Paulo, Rio de Janeiro e Belo Horizonte são as mais preparadas no momento, em relação a acreditação hospitalar pela ONA e/ou JCI-CBA. Os hospitais das demais sedes necessitam criar mecanismos de qualidade para obterem um dos tipos de acreditação com urgência. Somente assim vão evitar a imagem negativa dos serviços de saúde brasileiro aos estrangeiros que, por ventura, necessitarem de atendimento médico-hospitalar durante a Copa do Mundo de 2014.

Palavras-chave: Acreditação Hospitalar. Copa do Mundo de Futebol de 2014. Cidades Sede do Evento.

\footnotetext{
${ }^{1}$ Doutor em Engenharia de Produção pela Universidade Federal de Santa Catarina - UFSC. Professor do Dep. de Ciências da Administração, da Universidade Federal de Santa Catarina-UFSC . End.: Campus Universitário Trindade, Sala 226, Florianópolis -SC. CEP: 88010-970-Brasil. Email:mudimar@hotmail.com.

${ }^{2}$ Doutor em Engenharia Civil pela Universidade Federal de Santa Catarina-UFSC. Professor do Dep. de Eng. de Produção e Sistemas, da Universidade Federal de Santa Catarina-UFSC. End.: Faixa de Camobi, km 09, Campus Universitário, Sala 306, Santa Maria - RS. CEP: $97105-900$ - Brasil. E-mail:mail@adweise.de.

${ }^{3}$ Mestre em Ciências Contábeis pela Universidade Federal de Santa Catarina-UFSC. Professor do Dep. de Ciências da Administração da Universidade Federal da Fronteira Sul (UFFS). End.: Campus Universitário, Chapecó-SC. CEP: 89812-000-Brasil. E-mail: Charles_mcr@yahoo.com.br.

${ }^{4}$ Doutor em Engenharia de Produção pela Universidade Federal de Santa Catarina-UFSC. Professor Adjunto II do Dep. de Ciências da Administração da Universidade Federal de Santa Catarina - UFSC . End.: Campus Universitário Trindade, Sala 226, Florianópolis - SC. CEP: 88010-970 - Brasil. E-mail: allanplatt@yahoo.com.br.

Artigo recebido em: 10/11/2010. Aceito em: 29/04/2011. Membro do Corpo Editorial Científico responsável pelo processo editorial: Rolando Juan Soliz Estrada. 


\section{Introdução}

Os próximos dois anos serão de grandes desafios para os nossos Governos federal, estaduais e municipais. Principalmente, nas localidades em que se realizarão os jogos da copa do mundo 2014, bem como nos municípios circunvizinhos e nas regiões turísticas do país. No entanto, o anseio de melhor servir e levar uma imagem positiva ao exterior fez emergir diversos problemas estruturais que estão ocupando os noticiários das diversas mídias no país. As emissoras de televisão, por exemplo, vêm destinando blocos inteiros de seus jornais para destacarem as deficiências no sistema de transportes terrestres urbanos e interestaduais, bem como o caos dos aeroportos.

Hoje, os estádios dos jogos e a infraestrutura complementar deste espetáculo estão atrasados. Caso isso não se ajuste até 2014, vai ser repassada a ideia de desorganização e ineficiências nos serviços disponibilizados as autoridades, competidores e turistas que virão ao Brasil no referido evento. Como o Brasil é um país continental, jogos se realizarão em cidades distantes escolhidas pela Fédération Internationale de Football Association (FIFA), quais sejam (FIFA, 2011): Belo Horizonte (MG), Brasília (DF), Cuiabá (MT), Curitiba $(\mathrm{PR})$, Fortaleza (CE), Manaus (AM), Natal (RN), Porto Alegre (RS), Recife (PE), Rio de Janeiro (RJ), Salvador (BA) e São Paulo (SP).

No entanto, o eixo deste artigo está em outra esfera, isto é, a do atendimento médico-hospitalar aos participantes do evento. Em um evento desta magnitude sempre ocorrem imprevistos ou imperícias que levam as pessoas ao hospital. Os hospitais, as clínicas de pronto atendimento e as demais estruturas deste segmento estão sucateadas e de qualidade questionável. No entanto, a qualidade das unidades e serviços prestados nas organizações prestadoras de serviços de saúde poderia ter outra fotografia positiva se as normas de acreditação tivessem sido implantadas. Porém, o que presencia neste primeiro trimestre de 2011 é um cenário desolador na saúde, com hospitais sem infraestrutura tecnológica, lotados e distantes do que previsto pelo Manual Brasileiro de Acreditação, de 2010.

O referido manual tem a chancela do Ministério da Saúde e é gerenciado pela Organização Nacional de Acreditação (ONA) criada, em 1999, para balizar as ações de qualidade das organizações prestadoras de serviços de saúde brasileira (ONA, 2010). Além disso, os hospitais que já estão em um elevado padrão de qualidade podem solicitar o selo internacional de qualidade emitido pela Joint Commission on Accreditation of Hospitals (JCI), re- 
presentada no Brasil pelo Consórcio Brasileiro de Acreditação (CBA). Os padrões de análise são semelhantes, mas os graus de exigência diferem, havendo maior rigor no método de acreditação internacional (JCI, 2011).

Há lacunas entre os preceitos de qualidade destes documentos e a realidade dos hospitais brasileiros. Os reflexos desta lacuna poderão ser um dos fatores negativos aos olhos de autoridades, atletas e torcedores que virão participar da Copa do Mundo de 2014. Inclusive, poderá ser mais impactante que a infra-estrutura de estágios de futebol, malhas viárias terrestres e área. Por estas razões, realizou-se uma pesquisa para verificar como estão as cidades sedes futebolísticas para este evento, em relação à quantidade e classificação dos hospitais acreditados, até o dia 30 de abril de 2011.

\section{Procedimentos Metodológicos}

Do ponto de vista metodológico, a pesquisa foi do tipo exploratório, pois se buscou "[...] um entendimento sobre a natureza geral de um problema [...] com pouco conhecimento prévio daquilo que se pretende conseguir" (AAKER; KUMAR; DAY, 2001, p. 94). A abordagem foi de levantamento ou "Survey psicográfico" (MALHOTRA, 2001, p. 137), haja vista que se focou num ambiente intencional para se averiguar a situação da rede hospitalar, quanto a sua acreditação pela ONA ou pela JCI-CBA. A análise foi exclusivamente nas cidades sede da copa do mundo de 2014, no Brasil (AAKER, 2001; MALHOTRA, 2001). A pesquisa teve um tratamento quantitativo e qualitativo (CERVO; BERVIAN, 2007; ZANELLA, 2007).

O levantamento de dados foi de fontes secundárias, através da pesquisa pela internet, porque esta ferramenta possibilita agilidade com custos reduzidíssimos que beneficia estudos em casos de elevadas dispersões geográficas (MALHOTRA, 2001; AAKER; KUMAR; DAY, 2001).

O estudo teve um caráter transversal, pois se analisou o período do mês de abril de 2011, na contraposição hospitais que receberam selos o corte foi de análise foi feita no mês de abril de 2011, visando identificar os selos de qualidade emitidos pelas acreditadoras aos hospitais das localidades selecionadas (KERLINGER, 1980; RICHARDSON; PERES, 2007). 


\section{Histórico da Medicina}

Diversos estudos arqueológicos apresentam evidências em desenhos e documentos de civilizações remotas sobre a prática e "exercício da medicina". Para várias civilizações, a doença era tratada como castigo ou punição dos deuses para aqueles que não seguiam seus mandamentos ou então tratados como fenômeno místico associado a bruxarias. Reis, faraós, caciques e líderes espirituais usaram estas crendices para atingirem seus objetivos pessoais em nome do seu reinado (CAPRA, 1995; FOUCAULT, 1978; 1988).

No entanto, alguns líderes da antiguidade tiveram preocupações preventivas, curativas ou médicas que extrapolavam a simples noção da enfermidade ser a punição dos deuses. Moisés, por exemplo, definiu regras primárias de higienização de seus seguidores, bem como políticas de saneamentos básicos em lugares que passou com seus milhares de seguidores. Ele entendia que desta forma evitaria o surgimento ou proliferação de doenças contagiosas de pele e outras comuns na época, como a hanseníase ou lepra. Assim, instruía seu povo para cuidados básicos que deveriam ter na manipulação de alimentos e de cadáveres para evitar contágios. Ele pode ser tratado como um dos primeiros sanitaristas que se tem conhecimento histórico (PAIXÃO, 1960; ANTUNES, 1991).

Por sua vez, a civilização da Índia é uma das mais antigas do mundo. É dela que se tem a coleção mais antiga de livros do mundo (Rigveda), escrita por volta de 4.000 anos a.C. Essa coleção é composta de quatro livros, dos quais um deles descreve doenças milenares, como a tuberculose, hanseníase, conjuntivite, bem como descreve técnicas para a amputação de membros do corpo humano. Ressalta ainda técnicas médicas usadas por adeptos do hinduísmo que são adotadas até hoje, é lógico que dentro de novos parâmetros tecnológicos (CAPRA, 1995).

Já, a civilização Assírio-Babilônica contribuiu de forma significativa para os preceitos da medicina hodierna. Sua população documentou em peças de argila textos médicos datados de 3.000 anos a.C. Destacam-se dos achados desta civilização as escritas do Rei Hamurabi, sexto rei da primeira dinastia Babilônica. Ele definiu o Código de Hamurabi há cerca de 1.780 anos a.C. O referido código é composto de 282 artigos, dos quais se destaca a forma de remuneração e penalidades à negligência médica. Inclusive, há ressalvas sobre a ética profissional e a alerta sobre a forma de definição dos 
honorários médicos que deveria ser definido acordo com a classe social do doente (CAPRA, 1995).

A civilização egípcia é outra que contribuiu para o fortalecimento da medicina, registrando em papiros compêndios ou manuais médicos detalhados com classificações de doenças, descrições de intervenções cirúrgicas e vasta relação de catálogos sobre ervas e suas utilizações curativas. Não se pode esquecer que os Egípcios dominaram a arte de conservação de cadáveres pela mumificação, com a simbiose de técnicas médicas e de rituais religiosos que intrigam até hoje a medicina contemporânea (FOUCAULT, 1988; CAPRA, 1995).

Porém, em se tratando de civilizações antigas, a Grécia se destaca pelos expoentes que legou para as demais civilizações no tempo. Vale salientar que a medicina grega não se distanciou da religião, mas optaram por criar mitos ou estórias de caráter figurativo. Na mitologia Grega Apolo foi definido como o "deus do sol" e considerado "deus da saúde e da medicina" e seu filho Asclépios é considerado como o primeiro médico. Por esta razão, a arte de curar é creditada aos sacerdotes dos templos, na qual se pode endereçar a ideia de "grandes hospitais". Em meados do Século IV a.C., a Grécia presenteia a humanidade com um dos maiores médicos - Hipócrates. Ele nasceu na ilha de Cós, por volta de 460 anos a.C., tendo recebido grande parte de seu conhecimento médico na Trácia do famoso médico Heródico. Hoje, Hipócrates é apontado como o divisor histórico da medicina grega, isto é, a era anterior e posterior a sua existência e da mesma forma a cisão entre ciências médicas e religião ou crendice (GAARDER, 1995).

Em relação às civilizações orientais, a Chinesa é a que se destaca desde a antiguidade na arte do tratamento e prevenção de doenças. Com uma visão igualmente mística, mas com um pensamento diferente da maioria dos povos do ocidente, essa civilização tratou a medicina dentro de um patamar filosófico. Para a medicina chinesa o equilíbrio de polos simétricos da natureza contribuiria para a saúde ou doença dos indivíduos. Eles denominaram esses polos de princípio positivo ou masculino Yang e de princípio negativo ou feminino Ying. Em outras palavras, advogavam a harmonia desses polos que alicerçam o bem-estar, a tranquilidade e a saúde das pessoas, emprestando assim uma gama de informações e aplicações à homeopatia e das técnicas de acupuntura utilizadas até hoje (CAPRA, 1995). 


\section{Hospitais no Tempo}

Se a história da humanidade nos permite admitir que epidemias, guerras, superstições com adorações a deuses, seitas e religiões e, até mesmo a própria curiosidade foram alicerces da medicina no tempo, o mesmo parece ter acontecido com o surgimento dos hospitais, mas de forma mais lenta. Das civilizações que se destacaram ao longo da nossa existência, poucos relatos indicam espaços físicos destinados especificamente para a cura dos que necessitavam de atendimentos médicos. Ao que parece, o médico, além de conselheiro espiritual e adorado pelos seus conhecimentos na arte da cura, era também um viajante que procurava atender os seus pacientes em locais improvisados ou na sua própria residência.

Inicialmente, o hospital nasce como local de isolamento, mesmo já existindo na Grécia e na Roma Antiga, onde vários templos foram criados para homenagear Esculápio, deus romano que deu abrigo aos pobres, velhos e enfermos. Surge a ideia de hospedagem, isto é, local para atender viajantes doentes ou não, bem como os iatreuns (400 anos a.C.) que eram espaços públicos destinados a prática da medicina, mas sem o caráter religioso. Dessas ações foram criados os tabernae medicorum ou consultórios médicos, por volta de 250 anos a.C. (ANTUNES, 1991; BRAGA, 2000).

Do ponto de vista semântico, a expressão hospital originou-se do adjetivo hospes e da palavra latina hospitalis, que indica ser hospitaleiro, quem acolhe, agasalha ou hospeda alguém "hospedale". Com o advento da era cristã, o verbete hospital anexa-se à concepção Grega nosocomium que indica "lugar dos doentes e asilos dos enfermos" e nosodochium, ou seja, recepção de doentes. Com o passar do tempo e às alterações de concepções dos objetivos dos hospitais o foco deslocou-se como sendo o local destinado às práticas médicas e cuidados de modo adequado à cura de doentes (GONÇALVES, 1974; CAPRA, 1995).

É interessante esclarecer três verbetes que possuem radical idêntico, mas sentidos semânticos distintos (CAMPOS, 1944):

a) hospitium ou hospício: local ocupado por tempo indeterminado pelos doentes incuráveis, detentores de anomalias físicas ou mentais; 
b) hotel ou hospedaria: destinado a abrigar transeuntes e não doentes por um reduzido tempo, mediante o pagamento pelo uso do lugar; $e$

c) hospital: o espaço físico destinado para tratamento temporário de doentes.

Adverte Lisboa (1998) que várias expressões passaram a segmentar e agregar noções de tipos de hospitais, como por exemplo: o gynetrophyum (hospital para mulheres), o ptochodochium ou potochotrophium (asilo para pobres), o poedotrophium (asilo para crianças), gerontokomium (asilo para velhos), xenodochium ou xenotrophium (silo e refúgio para viajantes e estrangeiros), arginaria (asilo para os incuráveis), orphanotrophium (orfanato), hospitium (lugar onde hóspedes eram recebidos) e asylum (abrigo ou algum tipo de assistência aos considerados loucos).

Por outro lado, muitos creditam aos Hindus a expansão dos hospitais, em especial, a Buda (Sidartha Gautama) - o Iluminado. Ele foi responsável, direta e indiretamente, pela construção de vários hospitais e incentivou a formação de médicos, em diversos países circunvizinhos como: Ceilão e Japão (FOUCAULT, 1978; CAPRA, 1995).

Na Idade Média, os hospitais adquirem nova configuração e posicionamento filosófico. De um lado, o império islâmico detinha mais de 30 hospitais com características distintas dos hospitais europeus, pois abandonaram a preocupação religiosa e espiritual, que predominavam nestes estabelecimentos, para abordar os aspectos racionais e científicos (ANTUNES, 1991; CAPRA, 1995). Nesse período, há o fortalecimento do cristianismo e renovação da visão humanística que faz emergir posturas sociais relacionadas com a assistência aos pobres, doentes, idosos e peregrinos.

Desde então, multiplicaram-se as obras caritativas dos cristãos em grandes centros culturais, como Cesareia, Antióquia e Alexandria. São Basílio, por exemplo, construiu um dos primeiros e principais nosocomium, junto ao convento inaugurado no ano de 369, em Cesareia (Capadócia). Esse empreendimento era complexo, pois tinha escolas técnicas, manufaturas, residências para diáconos e diaconisas da ordem Parabolani que trabalhavam com os doentes em alas separadas para o tratamento de diversas enfermidades. No extenso reinado de Justiniano, além do crescimento de hospitais, é lançado o código que leva o seu nome e aborda a necessidade das especializa- 
ções nos hospitais, como os destinados para os cegos, leprosos, dentre outras (ANTUNES, 1991; FOUCAULT, 1988; LISBOA, 1998).

Na acepção de Foucault (1988, p. 99-111) o hospital, como instrumento terapêutico, é uma invenção nova que data do final do Século XVIII. Um dos alicerces deste tipo de hospital foi à reconstrução do Hôtel-Dieu de Paris, em 1780. Desde então, a concepção de hospital ganhou um novo panorama.

A história esclarece que não foi exclusividade cristã a proliferação do ensino da medicina e a construção de hospitais. Em Bagdá, por exemplo, foram inaugurados dois grandes hospitais, respectivamente, nos Séculos IV e V. Eles foram destruídos em 1258, quando a cidade foi invadida pelos Mongóis. O hospital do Cairo, construído em 1283, representava a forma geral dos hospitais do território ocupado pelo Islã. Já o exercício da medicina era reservado àqueles que eram aprovados, em provas orais pelos médicos ilustres da comunidade (FOUCAULT, 1978; ANTUNES, 1991; FOUCAULT, 1988).

No período áureo da medicina Árabe era severamente punido aquele que exercesse sem estar formado, fortalecendo o surgimento das escolas de medicina. O modelo hospitalar Islâmico é alicerçado por complexos sociocultural mesquita-escola-hospital, denominado de Bimaristan. A etimologia da palavra tem origem em bima, ou seja, pessoa doente, enferma, e stan, que significa casa. Portanto, casa para pessoas enfermas. Sob a influência desta religião há a separação das áreas de atendimento de homens e mulheres, bem como de alas específicas para cada tipo de patologia (FOUCAULT, 1978; CAPRA, 1995).

Tempos depois esta concepção das organizações hospitalares como meros terminais humanos se altera. Em meados do Século XVIII a ideia da cura passa a ser incorporada na cultura dos médicos, religiosos e demais profissionais que atuavam na saúde. Dentro deste raciocínio esclarece Foucault (1988, p. 83) que

O hospital que surge no Século XVIII significa o início de uma mudança com a instituição hospitalar anterior aonde o espaço, as rotinas, vão se forjar em outro sentido - o domínio do corpo e da cura dos sujeitos, inaugurando um rompimento com o hospital exclusão. 


\section{Histórico dos Hospitais no Brasil}

Como foi descrito, as religiões e exércitos foram decisivos para a formatação dos hospitais contemporâneos. No território brasileiro, essas organizações foram decisivas para o modelo hospitalar que existente. A Igreja Católica, por exemplo, foi responsável pela criação e a proliferação das Santas Casas. Já o Exército Português, em um primeiro momento, atendeu em hospitais improvisados nos seus navios e, somente em 1727, inaugura o hospital militar do Rio de Janeiro, no Morro de São Bento. Este empreendimento deu origem ao Hospital Real Militar (BURNS, 1963; ANTUNES, 1991).

Posteriormente, a sociedade civil se organiza e começa a investir na criação de hospitais comunitários, como a fundação das Beneficências Portuguesas. Com esta ação surge, em 1855, o Real Hospital Português de Beneficência do Recife (PE) e, 1857 e 1859, são criados, respectivamente, o Hospital Português de Salvador (BA) e as Beneficências Portuguesa do Rio de Janeiro e de São Paulo. Já em 1904, é fundado o Hospital Umberto I, em São Paulo (CAMPOS, 1944; DONNANGELO, 1975).

Com a chegada dos emigrantes italianos, alemães, japoneses, sírios e libaneses, a partir de 1917, a ampliação da rede hospitalar brasileira se acelera. Assim, em 1923, o Hospital Alemão da capital paulista foi inaugurado, um ano antes do Hospital Santa Cruz, mantido pela coletividade japonesa. Porto Alegre ganharia seu Hospital Alemão em 1927. Tempos depois são fundados o Hospital Sírio-Libanês, em 1965 e o Hospital Israelita Albert Einstein, em 1971, de São Paulo (LISBOA, 1998).

$\mathrm{O}$ risco das epidemias mundiais, associada à mudança de concepção dos governos brasileiro do Século XIX fez emergir investimentos destinados ao sistema de saúde pública, começando por políticas de saneamento básico e a criação de hospitais públicos que suprissem a necessidade da população carente. Um deles foi o hospital de Isolamento de São Paulo, inaugurado pelo poder público em 1880 , em pleno combate a um surto de varíola. O hospital levaria mais tarde o nome do sanitarista Emílio Ribas, que viveu de 1862 até 1925, afirmando-se centro de referência no combate às moléstias contagiosas. Nove anos depois da criação do Hospital de Isolamento, começava a funcionar no bairro carioca do Caju o Hospital São Sebastião, instituição pública também especializada no tratamento de doenças infecciosas (ANTUNES, 1991; LISBOA, 1998; BRAGA, 2000). 
Em 1942 e 1944, respectivamente, são inaugurados hospitais-escola como, o Hospital São Francisco de Assis vinculando-se a Faculdade de Medicina da Universidade Federal do Rio de Janeiro e o Hospital das Clínicas de São Paulo que se agregou à Faculdade de Medicina da USP. Nesse mesmo período, De modo concomitante, nascem em vários estados brasileiro de universidades federais contempladas com o Curso de Medicina fez evoluir, tanto o ensino da medicina quanto a crescimento de hospitais públicos associados a estas instituições de ensino superior (ANTUNES, 1991; LISBOA, 1998).

Supõe-se que, a gestão hospitalar não acompanhou o crescimento do número dessas instituições, principalmente pelas utilizações de técnicas de gestão distantes do crescimento populacional, sem falar nos escassos investimentos nas políticas preventivas dos governos municipais, estaduais e Federal. Por tudo isso é que, nas últimas duas décadas, a preocupação com políticas de qualidade e de acreditação hospitalar têm causado uma verdadeira corrente entre as organizações que atuam no sistema de saúde brasileira.

\section{Origens e Objetivos da Acreditação Hospitalar}

A partir da década de 50 do Século XX, inicia uma verdadeira corrida pela qualidade. Pode-se dizer que a filosofia da qualidade é uma exigência iniciada naqueles anos, que tem remodelado sistemas administrativos de organizações nos diversos segmentos econômicos e sociais. Para acompanhar essa corrente de excelência no atendimento e na credibilidade focados nos clientes foi criado nos Estados Unidos da América a Joint Comission on Accreditation of Hospitals (1951). De forma semelhante à Intenational Organization for Standardization, essa comissão foi idealizada para fornecer um padrão de atendimento, credibilidade e segurança aos pacientes, relacionados às diversas atividades inerentes ao sistema de saúde, como: os hospitais, os ambulatórios, as farmácias, dentre outros. O foco central foi a padronização e garantia da qualidade em todas as etapas e atividades ambulatoriais que participar pacientes e seus acompanhantes, principalmente nas fases em que houver atendimento médico hospitalar ou ambulatorial (SANCHES, 2003).

Tempos depois, a parceria entre o Colégio Americano de Médicos, a Associação Médica Americana, a Associação Americana de Hospitais e a Associação Médica Canadense fundaram a Joint Commission on Accreditation 
of Hospitals, a maior agência acreditadora dos Estados Unidos, na atualidade. A partir de 1999, o referido organismo de acreditação cria subsidiárias em vários países, como o Brasil, representado pelo Consórcio Brasileiro de Acreditação. Os padrões de acreditação internacional são desenvolvidos por uma força-tarefa composta por médicos, enfermeiros, administradores e especialistas em políticas públicas, dentro do que estabelecem os Manuais Internacionais de Acreditação (SANCHES, 2003).

Neste Manual, os padrões estão organizados em onze capítulos, que correspondem às funções mais importantes e comuns a todas as organizações hospitalares. Essas funções estão divididas em dois grandes grupos, as relacionadas aos cuidados prestados aos pacientes $e$ as relativas à gerência da organização (JCI/CBA, 2011), quais sejam: Funções relacionadas aos cuidados prestados aos pacientes: Acesso e Continuidade do Cuidado - ACC, Direitos dos Pacientes e Familiares - DPF, Avaliação do Paciente - AP, Cuidados ao Paciente - CP e Educação dos Pacientes e Familiares - EPF; e, Funções relativas à gerência da organização: Melhoria da Qualidade e Segurança do Paciente - QSP, Prevenção e Controle de Infecções - PCI, Governo, Liderança e Direção - GLD, Gerenciamento do Ambiente Hospitalar e Segurança - GAS, Educação e Qualificação de Profissionais - EQP e Gerenciamento da Informação - GI.

O Manual Brasileiro de Acreditação tem a chancela do Ministério da Saúde e foi concebido a partir a criação da Organização Nacional de Acreditação e seus parceiros. Ele fornece procedimentos que as organizações prestadoras de serviços de saúde precisam obter para serem classificadas entre um dos tipos de acreditação. É relevante destacar uma vez mais que a acreditação é uma metodologia desenvolvida para apreciar a qualidade da assistência médico-hospitalar dos serviços de atendimento e procedimentos de um hospital, com base em duas importantes variáveis, isto é: avaliação dos padrões de referência desejáveis: construídos por peritos e previamente divulgados; $e$, indicadores: instrumentos que o avaliador/visitador usa para constatar se os padrões foram observados ou estão presentes na instituição (ONA, 2010). O Manual Brasileiro de Acreditação Hospitalar avalia todos os serviços de um hospital geral. Há três níveis de atenção, práticas ou métodos esperados (ONA, 2010):

O primeiro passo é o Nível 1: Exigências Mínimas. Essas exigências estão associadas ao exercício profissional e características imprescindíveis para a prestação da assistência médico-hospitalar. $\mathrm{O}$ atendimento de todas as exigências deste nível propicia ao hospital receber o selo de Acreditado. 


\begin{tabular}{|c|c|}
\hline MA 1 Gestão e Liderança & MA 3 Diagnóstico \\
\hline $\begin{array}{l}\text { MA 1/1 Liderança } \\
\text { MA 1/2 Gestão de Pessoas } \\
\text { MA 1/3 Gestão Administrativa } \\
\text { MA 1/4 Gestão de Suprimentos } \\
\text { MA 1/5 Gestão da Qualidade }\end{array}$ & $\begin{array}{l}\text { MA 3/1 Processos Pré-Analíticos } \\
\text { MA 3/2 Processos Analíticos } \\
\text { MA 3/3 Processos Pós-Analíticos } \\
\text { MA 3/4 Métodos Diagnósticos } \\
\text { MA 3/5 Diagnóstico por Imagem }\end{array}$ \\
\hline MA 2 Atenção ao Paciente/Cliente & MA 4 Apoio Técnico \\
\hline $\begin{array}{l}\text { MA 2/1 Atendimento } \\
\text { MA 2/2 Internação } \\
\text { MA 2/3 Atendimento Ambulatorial } \\
\text { MA 2/4 Atendimento em Emergência } \\
\text { MA 2/5 Atendimento Cirúrgico } \\
\text { MA 2/6 Atendimento Obstétrico }\end{array}$ & $\begin{array}{l}\text { MA 4/1 Sistema de Informação do Clientel } \\
\text { Paciente } \\
\text { MA 4/2 Gestão de Equipamentos e Tecnolo- } \\
\text { gia Médico-Hospitalar } \\
\text { MA 4/3 Prevenção, Controle de Infecções e } \\
\text { Eventos Adversos } \\
\text { MA 4/4 Processamento e Liberação }\end{array}$ \\
\hline $\begin{array}{l}\text { MA 2/8 Tratamento Intensivo } \\
\text { MA 2/9 Mobilização de Doadores }\end{array}$ & $\begin{array}{c}\text { MA } 5 \text { Abastecimento e Apoio } \\
\text { Logístico }\end{array}$ \\
\hline $\begin{array}{l}\text { MA 2/10 Triagem de Doadores e Coleta } \\
\text { MA 2/11 Assistência Hemoterápica } \\
\text { MA 2/12 Terapia Dialítica } \\
\text { MA 2/13 Medicina Nuclear } \\
\text { MA 2/14 Radioterapia } \\
\text { MA 2/15 Terapia Antineoplásica } \\
\text { MA 2/16 Cardioanqiologia Invasiva e }\end{array}$ & $\begin{array}{l}\text { MA 5/1 Processamento de Roupas } \\
\text { MA 5/2 Processamento de Materiais e } \\
\text { Esterilização } \\
\text { MA 5/3 Armazenamento e Transporte } \\
\text { MA 5/4 Higienização } \\
\text { MA 5/5 Gestão da Segurança }\end{array}$ \\
\hline Hemodinâmica & MA 6 Infraestrutura \\
\hline $\begin{array}{l}\text { Videoscópicos } \\
\text { MA 2/18 Assistência Farmacêutica } \\
\text { MA 2/19 Assistência Nutricional }\end{array}$ & MA 6/1 Gestão da Estrutura Físico-Funcional \\
\hline
\end{tabular}

Quadro 1: Seções e Subseções da Norma Brasileira da Acreditação (2010)

Fonte: ONA (2010, p. 15 e 16)

O Nível 2: Padrões de qualidade no atendimento definem os hospitais que, além de cumprirem as exigências do Nível 1, adotam boas práticas na organização da assistência médico-hospitalar, bem como têm no paciente o foco central de sua atuação. O selo de acreditação emitido é o de Acreditado Pleno. 
Já, o Nível 3 ou Padrões de excelência corresponde aquele que busca apontar os hospitais que praticam a melhoria continua dos atendimentos $e$ têm padrões de excelência na prestação da assistência médico-hospitalar. Neste caso o selo recebido é Acreditado com Excelência. As Normas do Processo de Avaliação (NA) Hospitalar estão divididas em seis seções e várias subseções (MA), conforme pode ser visualizado no Quadro 1.

\section{Hospitais Acreditados nas Sedes da Copa do Mundo de 2014}

Os jogos da copa do mundo de 2014 no Brasil serão realizados em doze capitais do Brasil. As cidades escolhidas pela Fédération Internationale de Football Association (FIFA, 2011) para esta competição no país foram: Belo Horizonte (MG), com 2.375.151 habitantes, Brasília (DF) com 2.570.160 habitantes, Cuiabá (MT) com 551.098 habitantes, Curitiba (PR) 1.751.907 habitantes, Fortaleza (CE) com 2.452.185 habitantes, Manaus (AM) com 1.802.014 habitantes, Natal (RN) com 803.739 habitantes, Porto Alegre (RS) com 1.409.351habitantes, Recife (PE) com 1.537.704 habitantes, Rio de Janeiro (RJ) com 6.320.446 habitantes, Salvador (BA) com 2.675.656 habitantes e São Paulo (SP) com 11.253.503 habitantes, segundo o censo do Instituto Brasileiro de Geografia e Estatística realizado em 2010 (IBGE, 2011).

Quanto aos tipos de Acreditação dos hospitais brasileiro situados nas sedes dos jogos da copa do mundo de 2014, a situação atual é preocupante. Há pouco mais de três anos do referido evento os dados coletados (Tabela 1) demonstra que a situação de risco de emergência hospitalar de turistas em algumas sedes é temeroso, pois a acreditação hospitalar, mesmo após, uma década de sua implantação ainda não atingiu todas as regiões como deveria.

A Figura 1 permite verificar que a Acreditação hospitar pela metodologia brasileira defendida pela Organização Nacional de Acreditação (ONA) tem na cidade de São Paulo há um total de 63 hospitais acreditados, sendo 15 acreditados, 21 hospitais acreditado Pleno e 27 Acreditados Com Excelência. Belo Horizonte que conta com 32 hospitais acreditados, dos quais, 21 são Acreditado Pleno e 11 já obtiveram o selo de Acreditado com Excelência. 


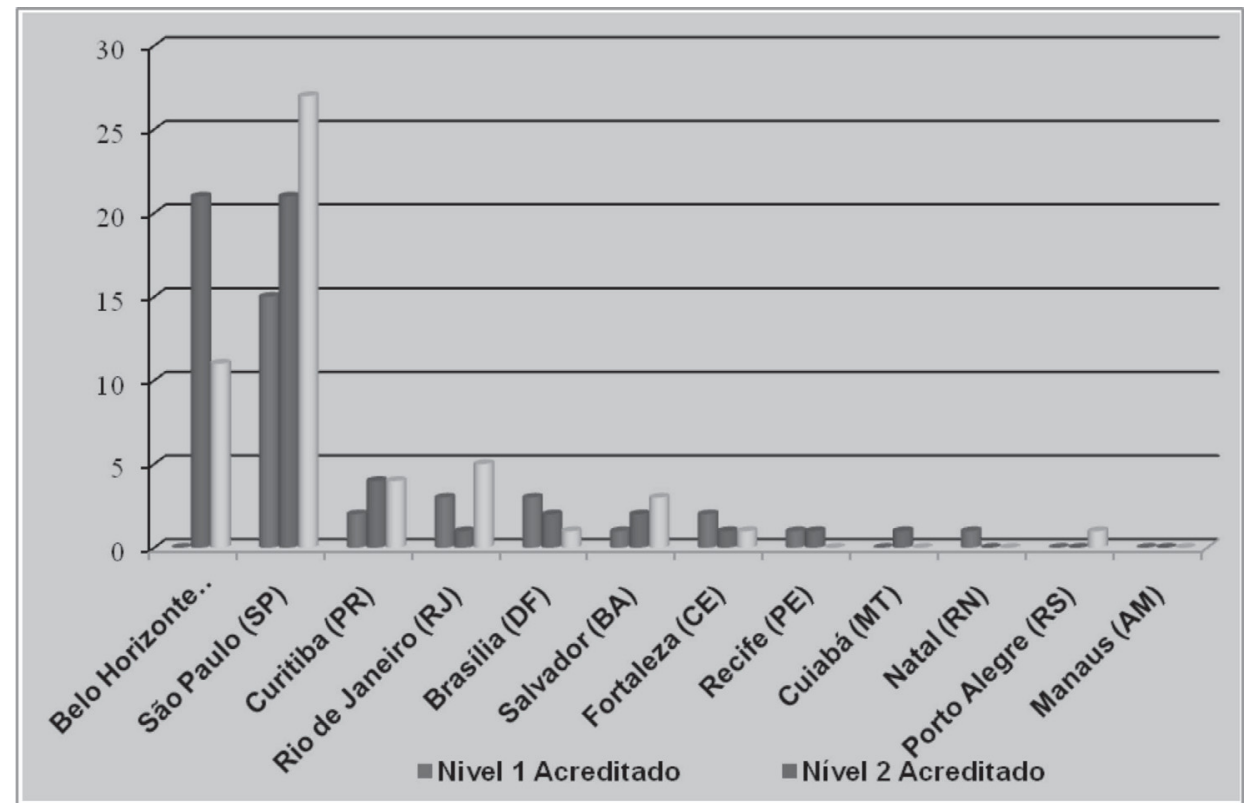

Figura 1: Número de Hospitais Acreditados pela Metodologia ONA, até 31 de abril de 2011

Fonte: Adaptada de < https://www.ona.org.br/OrganizacoesCertificadas/260 > . Acesso em: 31 abr. 2011.

No outro extremo se verifica a situação das demais sedes que não possuem no momento uma dezena de hospitais com acreditação da ONA (Figura 1 e Tabela 1). Sedes como Recife, Cuiabá, natal, Porto Alegre apresentam um baixíssimo índice de hospitais acreditados, mas serão sedes com um grande número de turistas que circularam nestas localidades e, portanto, passíveis de contratempos com a sua saúde. Manaus, por exemplo, não tem nenhum hospital acreditado em dez anos do início desta norma de qualidade. No entanto, pressupõe-se que seja uma das sedes mais visitadas pela mágica que a selva amazônica cria aos turistas estrangeiros.

Da mesma forma se buscou identificar os hospitais destas sedes que tenham obtido a acreditação internacional, isto é, pelo Joint Commission International Accreditation Standards for Hospitals (JCI), através do Consórcio Brasileiro de Acreditação (CBA). Os dados levantados apontam novamente para uma situação preocupante e delicada que precisa ser cobrada pelos governantes públicos. A Tabela 1 e a Figura 2 permitem constatar que em apenas três cidades da Copa do Mundo de 2014, os hospitais já foram aprovados pela metodologia de qualidade hospitalar da JCI-CBA: São Paulo, Rio de Janeiro e Porto Alegre. 
Visualize na Figura 2, que São Paulo tem nove hospitais Acreditados pela JCI-CBA e dois serviços complementares hospitalares acreditados pela metodologia internacional, como o sistema e padrão de qualidade de transporte de enfermos, totalizando 11 organizações prestadoras de serviços de saúde com este selo de qualidade.

A outra cidade que tem hospitais acreditados pela metodologia internacional de qualidade é Rio de Janeiro. Os cariocas contam com sete hospitais classificados pelo JCI-CBA como certificados e seis organizações complementares de saúde também obtiveram esse padrão de qualidade, isto é, em atividades correlacionadas à saúde dos clientes (Figura 2).

A terceira cidade sede que tem um hospital acreditado pela metodologia internacional de acreditação (JCI-CBA) é Porto Alegre (Figura 2). No entanto, esse número é ínfimo se imaginarmos que em caso de urgência ou fato inesperado essa capital conta no total com apenas dois hospitais com selos de qualidade, sendo o outro selo emitido pela ONA.

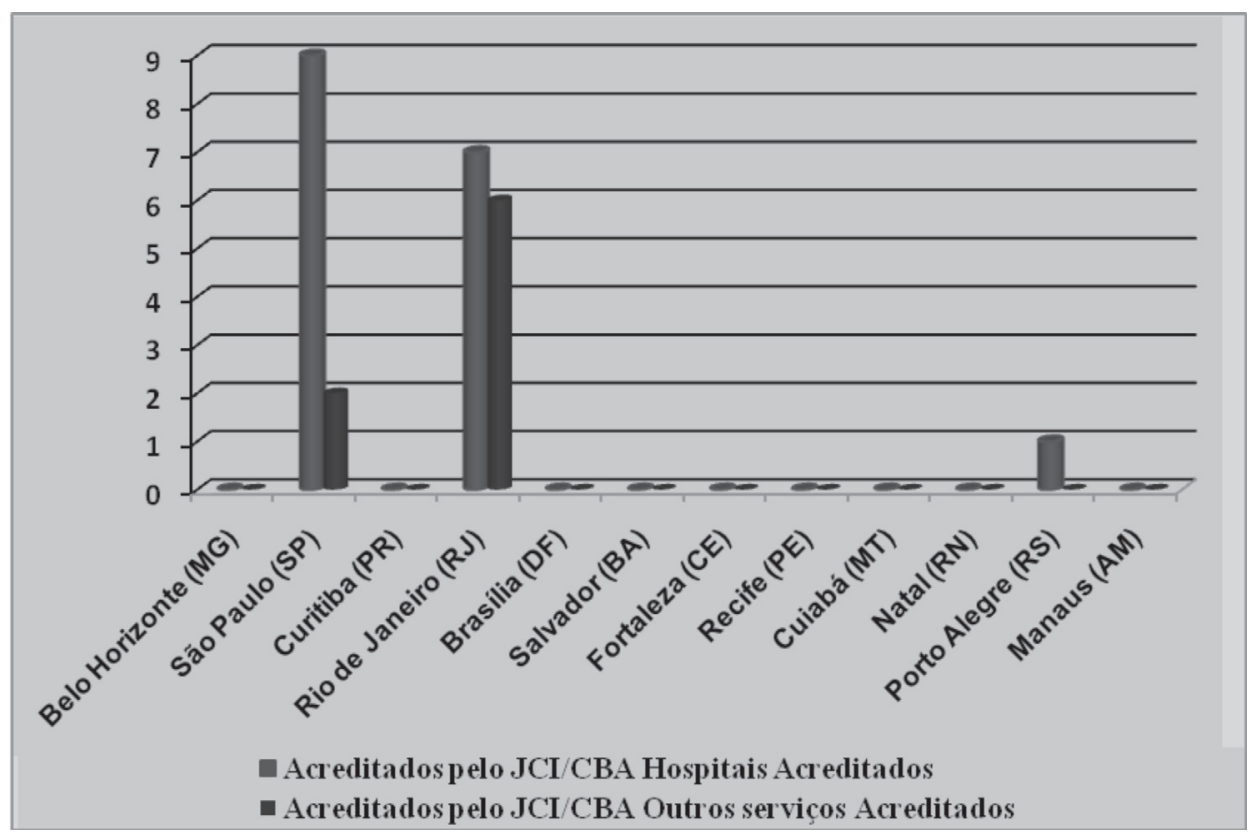

Figura 2: Número de Hospitais Acreditados pela Metodologia JCI-CBA, até 31 de abril de 2011

Fonte: Adaptada de <http://pt.jointcommissioninternational.org/enpt/JCI-AccreditedOrganizations > . Acesso em: 31 abr. 2011. 
Da mesma forma, os dados da Tabela 1 e Figura 2 mostram que nas demais cidades sede da Copa do Mundo de 2014, não há nenhum hospital com o selo internacional de Acreditação. Essa constatação é preocupante, pois requer ações técnico-administrativas urgentes dos gestores hospitalares visando a acreditar seus hospitais até 2014. É relevante destacar que o total de hospitais acreditados pela ONA no Brasil, até o dia 30 de abril de 2011, é de apenas 272 hospitais, destes, 135 estão nas sedes do evento supramencionado. Portanto, se os turistas e delegações dos competidores optarem por ficar em outras cidades do país, eles correm o risco de optarem por uma localidade sem a qualidade adequada na prestação de serviços de saúde.

Tudo leva a crer que outras cidades serão rotas turísticas. Dos pontos mais visitados, apenas Foz de Iguaçu (PR) tem um hospital acreditado, ampliando a relevância de ações imediatas sobre essa questão. Esses dados são extremamente preocupantes.

Tabela 1: Tipos de Acreditação dos Hospitais das Sedes da Copa do Mundo de 2014

\begin{tabular}{|c|c|c|c|c|c|c|c|c|}
\hline \multirow[b]{2}{*}{$\begin{array}{c}\text { Copa do Mundo } 2014 \\
\text { Cidades } \\
\text { Sede dos Jogos }\end{array}$} & \multicolumn{3}{|c|}{ Classificação e Qualificação Hospitalar } & \multirow{2}{*}{$\begin{array}{l}\text { Hospitais } \\
\text { Acreditados } \\
\text { ONA }\end{array}$} & \multicolumn{2}{|c|}{ Acreditados JCI/CBA } & \multirow{2}{*}{$\begin{array}{l}\text { Hospitais } \\
\text { Acreditados } \\
\text { JCI/CBA }\end{array}$} & \multirow[b]{2}{*}{ Tota } \\
\hline & $\begin{array}{c}\text { Nível 1 } \\
\text { Acreditado }\end{array}$ & $\begin{array}{c}\text { Nível 2 } \\
\text { Acreditado } \\
\text { Pleno }\end{array}$ & $\begin{array}{c}\text { Nível } 3 \\
\text { Acreditado } \\
\text { com } \\
\text { Excelência }\end{array}$ & & $\begin{array}{l}\text { Hospitais } \\
\text { Acreditados }\end{array}$ & $\begin{array}{c}\text { Outros } \\
\text { Serviços } \\
\text { Acreditados }\end{array}$ & & \\
\hline Belo Horizonte (MG) & 0 & 21 & 11 & 32 & 0 & 0 & $\mathbf{0}$ & 32 \\
\hline São Paulo (SP) & 15 & 21 & 27 & 63 & 9 & 2 & 11 & 74 \\
\hline Curitiba (PR) & 2 & 4 & 4 & 10 & 0 & 0 & $\mathbf{0}$ & 10 \\
\hline Rio de Janeiro (RJ) & 3 & 1 & 5 & 9 & 7 & 6 & 13 & 22 \\
\hline Brasília (DF) & 3 & 2 & 1 & 6 & 0 & 0 & O & 6 \\
\hline Salvador (BA) & 1 & 2 & 3 & 6 & 0 & 0 & 0 & 6 \\
\hline Fortaleza (CE) & 2 & 1 & 1 & 4 & 0 & 0 & $\mathbf{0}$ & 4 \\
\hline Recife (PE) & 1 & 1 & 0 & 2 & 0 & 0 & $\mathbf{0}$ & 2 \\
\hline Cuiabá (MT) & 0 & 1 & 0 & 1 & 0 & 0 & 0 & 1 \\
\hline Natal (RN) & 1 & 0 & 0 & 1 & 0 & 0 & $\mathbf{0}$ & 1 \\
\hline Porto Alegre (RS) & 0 & 0 & 1 & 1 & 1 & 0 & 1 & 2 \\
\hline Manaus (AM) & 0 & 0 & 0 & $\mathbf{0}$ & 0 & 0 & $\mathbf{0}$ & $\mathbf{0}$ \\
\hline $\begin{array}{r}\text { Total } \\
\end{array}$ & 28 & 54 & 53 & 135 & 17 & 8 & 25 & 160 \\
\hline
\end{tabular}

Fonte: Adaptada de ONA (2011) e de JCI (2011)

A realidade exposta (Tabela 1 ) permite admitir que os preceitos de qualidade descritos pela ONA e JCI-CBA não atendem as exigências dos demais hospitais das cidades sede da Copa do Mundo de 2014, quais sejam: funções relacionadas aos cuidados prestados aos pacientes desde seu acesso e continuidade do cuidado, direitos dos pacientes e familiares, avaliação do paciente, cuidados ao paciente e educação dos pacientes e familiares sobre o tratamento doméstico complementar e, ainda em funções relativas à gerência da organização hospitalar como a melhoria da qualidade e segurança do 
paciente, prevenção e controle de infecções, governo, liderança e direção, gerenciamento do ambiente hospitalar e sua segurança, educação e qualificação de seus profissionais e o gerenciamento da informação. Além disso, não atendem qualidade exigida aos gestores, conforme foi ressaltado no Quadro 1 do presente artigo. Como se percebe, se o evento fosse hoje e se algum imprevisto coletivo a saúde dos turistas e da própria população ocorresse nas sedes em que serão realizados os jogos a possibilidade de vexame e de uma imagem negativa ao exterior é real.

\section{Considerações Finais}

As exigências de um evento de proporções mundial como a copa do mundo extrapola os aspectos burocráticos e de obras física de estádios, estradas, metrôs, praças e de atrativos de entretenimento. Uma copa do mundo traz pessoas de todos os cantos do globo terrestre que esperam encontrar conforto e segurança. O conceito de segurança precisa ser dimensionado para além do aspecto policial, mas atingir o patamar da saúde dos visitantes. Um dos aspectos que levam a esta segurança é a garantia de qualidade no atendimento do cliente ou paciente. Por essas razões emergiram padrões de atendimento de qualidade em saúde denominados de acreditação. O que se verificou até o dia 30 de abril de 2011, é que no Brasil a maioria das sedes da Copa do Mundo de 2014 não está preparada qualitativamente para atender os clientes, sob o enfoque de acreditação hospitalar como garantia de serviço personalizado de qualidade.

Observe que somente São Paulo, Belo Horizonte e Rio de Janeiro estão se preparando para esse evento. Nas referidas sedes o número de hospitais acreditados é considerado bom. Nas demais localidades a realidade é muito diferente e preocupante, pois os seus hospitais não estão se preocupando em tomar medidas que lhes garanta selo de qualidade que mude a cultura e concepção do corpo geral de profissionais que labutam na saúde. Para os turistas que necessitarem atendimentos de urgências a falta de qualidade no atendimento pode caracterizar a saúde no grande vilão da imagem do Brasil neste evento. Vale lembrar que a imprensa mundial estará usando espaços jornalísticos ociosos com reportagens complementares, dentre eles a situação da saúde hospitalar brasileira. É um assunto para se pensar e agir! 


\section{Accreditation of Hospitals in Brazilian Cities of the Soccer World Cup in 2014}

\section{Abstract}

The article deals with the Hospital Accreditation as a quality parameter of hospitals in Brazil and the world. The focus was to identify how the hospitals of the host cities of the FIFA World Cup in 2014 are classified by the National Accreditation Organization (ONA) and Joint Commission on Accreditation of Hospitals (JCI) the Brazilian Consortium for Accreditation (CBA). The Brazilian Manual of Accreditation establishes three stamps of hospital quality: Level 1: Accredited, Level 2: Fully Accredited and Level 3: Accredited with Excellence. From the methodological point of view the study was regarded as an exploratory approach, with a kind psychographic survey, with the intentional collection of data, ie the host cities. The research had a qualitative and quantitative treatment. Data were collected during March and April 2011 through the official websites of the ONA, JCI-CBA and FIFA on the Internet. It was concluded that the cities of Sao Paulo, Rio de Janeiro and Belo Horizonte are the best prepared in time for hospital accreditation by ONA and / or JCI-CBA. The hospitals of other offices need to create mechanisms to achieve a quality accreditation of types urgently. Only thus will avoid the negative image of the Brazilian health services to foreigners who, by bad luck, requiring medical and hospital during the World Cup 2014.

Key words: Accreditation of hospitals. Soccer world cup in 2014. Host cities.

\section{Referências}

AAKER, D. A.; KUMAR, V.; DAY, G. S. Pesquisa de Marketing. São Paulo: Atlas, 2001.

ANTUNES, J. L. F. Hospital: instituição e história social. São Paulo: Letras e Letras, 1991.

BRAGA, D. Acidente de trabalho com material biológico em trabalhadores da equipe de enfermagem do Centro de Pesquisas Hospital Evandro Chagas: um olhar da saúde do trabalhador. 2000. 86 p. Dissertação (Mestrado) - Fundação Oswaldo Cruz, Escola Nacional de Saúde Pública, Rio de Janeiro. 2000. 
BURNS, E. M. História da civilização ocidental. Porto Alegre: Globo, 1963.

CAMPOS, E. de S. História e evolução dos hospitais. Rio de Janeiro: Ministério da Educação e Saúde, Departamento Nacional de Saúde, 1944.

CAPRA, F. O Ponto de Mutação: a ciência, a sociedade e a cultura emergente. São Paulo: Cultrix, 1995.

CBA - Consórcio Brasileiro de Acreditação. Informações sobre o Consórcio Brasileiro de Acreditação. Disponível em: < http://www.cbacred.org.br/ site/empresa.php>. Acesso em: 22 fev. 2011.

CERVO, A. L.; BERVIAN, P. A.; SILVA, R. da. Metodologia científica. 6. ed. São Paulo: Pearson Prentice Hall, 2007.

DONNANGElO, M. C. F. Medicina e sociedade. São Paulo: Pioneira, 1975.

FIFA - Fédération Internationale de Football Association. Copa do mundo de futebol 2014. Disponível em: < http://www.fifa.com/worldcup/index.html>. Acesso em: 15 fev. 2011.

FOUCAULT, M. História da loucura. São Paulo: Perspectiva, 1978.

. Microfísica do poder. 7. ed. Rio de Janeiro: Graal, 1988.

GAARDER, J. O mundo de Sofia: romance da história da filosofia. São Paulo: Companhia das Letras, 1995.

GONÇALVES, R. B. M. Medicina e história: raízes sociais do trabalho médico. 1979. 209p. Dissertação (Mestrado), área de medicina preventiva da Faculdade de Medicina da USP - Universidade de São Paulo, São Paulo. 1979.

IBGE - Instituto Brasileiro de Geografia e Estatística. Censo 2010. Disponível em: <http://www.ibge.gov.br/home/estatistica/populacao/censo2010/ sinopse_tab_uf_pdf.shtm>. Acesso em: 10 fev. 2011.

JCI-CBA - Manual Internacional de Acreditação. Disponível em: <2007http://pt.jointcommissioninternational.org/enpt/Programs-Hospitals/>. Acesso em: 19 fev. 2011.

KERLINGER, F. N. Metodologia da pesquisa em ciências sociais: um tratamento conceitual. São Paulo: EDUSP, 1980. 
LISBOA, T. C. Lavanderia hospitalar: reflexão sobre fatores motivacionais. 1998. 138p. Tese (Doutorado) - Universidade Mackenzie, São Paulo, 1998.

MALHOTRA, N. K. Pesquisa de Marketing: uma orientação aplicada. Porto Alegre: Bookman, 2001.

ONA - Organização Nacional de Acreditação. Normas para o processo de avaliação: avaliação das Organizações Prestadoras de Serviços Hospitalares. Brasília: ANVISA, 2010.

PAIXÃO, W. Páginas de história da enfermagem. 2. ed. Rio de Janeiro: Buccini, 1960.

RICHARDSON, R. J.; PERES, J. A. de S. Pesquisa social: métodos e técnicas. São Paulo: Atlas, 2007.

SANCHEZ, K. R. Sistema Integrado de Gestão em Organizações Hospitalares: um enfoque dirigido à Acreditação, NBR ISSO 9001, NBR ISSO 14001 e BS 8800. 2003. 260 f. Dissertação (Mestrado em Administração) Universidade Federal de Santa Catarina. Florianópolis, 2003.

ZANELLA, L. C. H. Metodologia de pesquisa. Florianópolis: Departamento de Ciências da Administração/UFSC, 2007. 